\title{
Health Care Behaviors and Decision-Making Processes Among Enrollees In A State High Risk Insurance Pool: Focus Group Findings
}

\author{
Jean P. Hall, PhD* \\ Shawna L. Carroll, MA, MPH \\ Janice M. Moore, MA, MBA, MSW \\ Division of Adult Studies \\ University of Kansas
}

* Corresponding Author

Dr. Jean P. Hall

1122 West Campus Road, Rm 517

Lawrence, KS 66045-3101

Phone: 785-864-7083

Fax: 785-864-7799

Email: jhall@ku.edu

Published in: 2010, American Journal of Health Promotion, DOI:

http://dx.doi.org/10.4278/ajhp.080613-QUAL-91

\section{Acknowledgment}

This study was funded by the Kansas Health Policy Authority through a grant from the U.S. Department of Health and Human Services, Centers for Medicare and Medicaid Services (11-P-92389/7-01). 


\begin{abstract}
Purpose

To better understand the relationship between health insurance coverage and health care behaviors of persons with potentially disabling conditions enrolled in a state high risk insurance pool.
\end{abstract}

\title{
Approach or Design
}

Six focus groups with risk pool enrollees in two sites.

\section{Setting}

Suburban areas in the state of Kansas.

\section{Participants}

Forty-two individuals ages 29 to 62 years, all with potentially disabling physical or mental health conditions.

\section{Method}

Qualitative analysis of focus group transcripts using pile sorting and theme identification.

\section{Results}

High premiums and deductibles limit participants' ability to afford basic health services and access to prescription medications despite their middle-class socioeconomic status. Participants report delaying or forgoing needed medical care due to lack of coverage and/or out-of-pocket costs. They employ numerous and potentially dangerous strategies to minimize costs, especially for prescription medications. Some report "saving up" needed procedures until their total costs will exceed that year's deductible.

\section{Conclusion}

Individuals in the risk pool were making medical decisions on the basis of cost rather than need. Many shared stories of medical complications as a result of delayed care and most expressed stress related to the difficulty of making decisions about their care and use of prescribed medications. The individual, nongroup insurance market, with its higher out-of-pocket costs, may not meet the needs of people with chronic health conditions. 


\section{PURPOSE}

High risk pools are nongroup state-established health insurance programs for people who do not qualify for Medicare or Medicaid, cannot access group health insurance, and who have pre-existing health conditions that make it difficult or impossible for them to obtain other individual coverage. ${ }^{1}$ Nationally, more than 190,000 persons are enrolled in 34 state high risk pools. ${ }^{2}$ Modeled after the individual market, high risk pools typically have higher premiums, deductibles, and co-pays, and more limited coverage than do employer-based group plans. Current as well as past research suggests that higher rates of cost sharing result in underutilization of appropriate services and medications, with poorer health outcomes. ${ }^{3-11}$ These behaviors could be especially problematic in a population that experiences pre-existing conditions, with even greater potential for negative outcomes. ${ }^{12}$

This paper describes health care behaviors of individuals with high risk pool coverage prior to their participation in a research demonstration sponsored by the federal Centers for Medicare and Medicaid Services and the State of Kansas, the Kansas Demonstration to Maintain Independence and Employment (DMIE). ${ }^{13}$ DMIE is testing the hypothesis that comprehensive health and supportive services provided to people with potentially disabling conditions can forestall or prevent disability and improve their quality of life. Because Kansas' high risk pool members historically transition to Social Security disability programs at eight times the rate of the general population, the study is focused on risk pool beneficiaries who are employed, potentially eligible for Social Security in the event of disability, and have at least five years until they reach Medicare age. ${ }^{14}$ One important facet of the study is to understand experiences of this population in relation to their health insurance coverage. We present here focus group findings about health care behaviors and decision-making processes among our study participants before 
receiving the benefits of the DMIE intervention (i.e., baseline descriptions). We also report some early indications of changes in health care behaviors associated with the intervention.

\section{Health Insurance Coverage in Relation to Health Care Behaviors}

Research supports the assumption that health insurance coverage is an important element in promoting wellness as well as decreasing morbidity and mortality. For example, a recent survey found that having health insurance was associated with higher utilization of a wide array of clinical preventive services (e.g., blood pressure testing, cholesterol monitoring, colonoscopy screening, Pap smears, mammography). ${ }^{15}$ Even as economists assume that insurance plans that require greater consumer decision making via increased cost sharing will result in more efficient and appropriate use of services, research indicates that in some contexts cost sharing can lead to inefficiency and poorer health outcomes. ${ }^{5,16,17}$

Several studies demonstrate that higher rates of cost sharing result in underutilization of appropriate services and medications, with poorer health outcomes. Hsu et al., for example, reported poorer physiological outcomes (e.g., high blood pressure), more emergency department utilization, and greater mortality were associated with higher prescription drug cost sharing. ${ }^{18}$ The RAND health insurance experiment found that consumers faced with higher cost sharing reduced utilization of health services across the board, rather than choosing to drop lower-value services and retain higher-value services. ${ }^{9}$ Likewise, quantitative analyses have found increased cost sharing reduces utilization of important medications used for managing chronic conditions (e.g., diabetes, hypertension, high cholesterol). ${ }^{6,7}$ Conversely, Chernew et al. found that reduced cost sharing for prescription drugs increased adherence to treatment regimes for chronic conditions. ${ }^{19}$ Low income and elderly consumers demonstrated the greatest sensitivity in the relationship between to copayments and medication adherence. ${ }^{3}$ 
Quantitative research of the economics of health insurance in relation to health care utilization is valuable to health policy makers. However, much less is known about the underlying attitudes and experiences of consumers who must make trade-offs between high costs and needed health care. Chernew called for greater investment in "social science research that helps us understand patient behavior." ${ }^{16}$ Our goal here is to shed light on the attitudes and experiences of persons with potentially disabling conditions enrolled in a state high risk health insurance pool.

\section{What are High Risk Pools?}

High risk pools are government subsidized, nongroup insurance programs for people with chronic physical or mental health conditions who are unable to access group health insurance and who have difficulty obtaining insurance from private providers. ${ }^{20}$ They are considered the insurers of last resort for more than 190,000 enrollees nationally. ${ }^{21-23}$ High risk pools offer coverage similar to that of other nongroup plans with some variation among the 34 states that offer them. ${ }^{21,23}$ Costs also vary, but high risk pools tend to have steep premiums that increase with an enrollee's age and are coupled with significant co-insurance levels and deductibles, and, often, annual and lifetime caps for benefits. $1,24,25$

Nationally, the average high risk pool enrollee has four to six chronic and potentially lifethreatening illnesses. ${ }^{26}$ Risk pool participants are sometimes described as the "sickest of the sick," and are especially likely to experience conditions that lead to disability. ${ }^{25,26}$

The combination of high out-of-pocket costs, caps on coverage, and limited plan benefits, may discourage enrollees from using needed medical services, potentially resulting in poor longterm health outcomes and even disability. ${ }^{27,28}$ Although no national figures exist, a recent 
retrospective review determined Kansas high risk pool members transitioned to Social Security

Disability Insurance (SSDI) at a rate eight times that of the general population. ${ }^{14}$

In Kansas people are able to access the high risk pool if they have been turned down for coverage by two different insurance companies, offered health insurance that permanently excludes coverage for a pre-existing condition, or are unable to find private health insurance coverage that is cheaper than the pool's. Premiums for the pool are high and are currently $133 \%$ of the standard rate charged for similar coverage in the private market. In addition, participants cannot be eligible for Medicaid or Medicare coverage.

Some of the more common conditions experienced by Kansans in the high risk pool include advanced heart disease, chronic obstructive pulmonary disease, cancer, congestive heart failure, diabetes, depression, and spinal disorders, all of which have the potential to become disabling without access to adequate and appropriate health care.

\section{METHOD}

To better understand experiences of high risk pool members we conducted six focus groups with a total of 42 DMIE participants. The study design and procedures were approved by the University of Kansas institutional review board, the Center for Research Human Subjects Committee. This paper reports health care behaviors, experiences, and attitudes of study participants at baseline, that is, prior to receiving the DMIE intervention, and in some cases, early changes in behavior after receiving the study benefits.

\section{Demonstration to Maintain Independence and Employment (DMIE)}

While the health care behaviors of high risk pool members are the focus of this paper, the DMIE program defines the study sample, thus we describe it briefly here. Participation in the DMIE was limited to persons enrolled in the Kansas high risk pool for at least six months who 
were aged 18 to 60 , working at least 40 hours per month, and experiencing a potentially disabling health condition (e.g., mental illness, heart disease, cancer, diabetes). The DMIE employs an experimental design in which we randomly assigned participants to either a control or intervention group. Participants in the control group retain standard high risk pool insurance while those in the intervention group receive Medicaid-like coverage as a wraparound to their high risk pool coverage, including premiums that are subsidized to a flat premium of $\$ 152$ per month; no deductibles or coinsurance; copayments of only $\$ 3$; additional dental, vision, and hearing coverage; increased coverage for services such as mental health, prescriptions, home health, and preventive care; and vocational rehabilitation and worksite assessment services. At the time of the focus group sessions, 416 individuals had enrolled in the study.

\section{Sample Selection}

By contacting individuals who indicated an interest in focus group participation on their DMIE application forms, we drew a convenience sample of 42 individuals, or $10 \%$ of the DMIE participants. Table 1 demonstrates the comparability of the focus group participants to the DMIE participants. Overall, the groups are very similar. The focus group members differed significantly $(p<.01)$ from the DMIE study sample in only one demographic category: education. Focus group participants had attained higher levels of education.

Informed consent for focus group participation was included in the master informed consent agreement signed at the beginning of the study. In this consent, participants also made available baseline demographic data and gave us permission to access their health insurance plan administrative data (e.g., claims and plan information such as premium and deductible levels). 


\section{Table 1}

Sample Demographic Characteristics

\begin{tabular}{|c|c|c|}
\hline $\begin{array}{l}\text { Characteristic } \\
\text { Gender: percent female }\end{array}$ & $\begin{array}{c}\text { DMIE } \\
\text { participants } \\
(n=416) \\
49.5\end{array}$ & $\begin{array}{c}\text { Focus group } \\
\text { participants } \\
(n=42) \\
52.4\end{array}$ \\
\hline Mean age in years & 50.6 & 52.0 \\
\hline \multicolumn{3}{|l|}{ Age distribution: percent of $n$} \\
\hline $18-29$ & 4.3 & 2.4 \\
\hline $30-39$ & 5.0 & 4.8 \\
\hline $40-49$ & 26.4 & 31.0 \\
\hline $50-59$ & 51.4 & 40.5 \\
\hline $60-61^{*}$ & 12.7 & 21.4 \\
\hline \multicolumn{3}{|l|}{$\begin{array}{l}\text { Educational attainment: } \\
\text { percent of } n \dagger\end{array}$} \\
\hline $\begin{array}{l}\text { More than 4-year college } \\
\text { degree }\end{array}$ & 22.5 & 42.9 \\
\hline 4-year college degree & 22.0 & 23.8 \\
\hline Some college/ & 35.6 & 26.2 \\
\hline \multicolumn{3}{|l|}{ 2-year degree } \\
\hline High school diploma & 17.9 & 7.1 \\
\hline Less than high school diploma & 2.0 & 0.0 \\
\hline \multicolumn{3}{|l|}{ Marital status: percent of $n$} \\
\hline Married & 56.7 & 59.5 \\
\hline Single & 23.8 & 19.0 \\
\hline Divorced & 19.5 & 21.4 \\
\hline Mean $(S D)$ own annual income $\dagger$ & $\begin{array}{l}\$ 49,970 \\
(62,436)\end{array}$ & $\begin{array}{l}\$ 47,380 \\
(45,705)\end{array}$ \\
\hline $\begin{array}{l}\text { Mean }(S D) \text { household annual } \\
\text { income } \dagger\end{array}$ & $\begin{array}{l}\$ 69,990 \\
(71,436)\end{array}$ & $\begin{array}{l}\$ 67,000 \\
(47,625)\end{array}$ \\
\hline
\end{tabular}

*Maximum age allowed was 61 so that study participants would not become Medicare eligible in the course of the study.

$\dagger$ Self-reported in a survey. 


\section{Setting and Procedures}

During March and April, 2007, we conducted six two-hour focus group sessions, three comprised of intervention group participants and three of control group participants. The intervention group participants had received DMIE benefits between three to twelve months. The largest group had 12 participants, the smallest two, and the median per group was nine. Four of the sessions took place in Overland Park, KS, a suburb of Kansas City, and two in Lawrence, KS. Participants received a \$25 stipend and, if they traveled more than 10 miles, mileage reimbursement. Sessions were scheduled at different times of day to accommodate participant work schedules.

Two researchers conducted all the focus group sessions. The principal investigator had previously conducted more than 30 focus groups, including those with welfare participants, people with various mental and physical disabilities, service providers, and youth. The secondary researcher, who listened to and tape recorded all the sessions, was a trained social worker.

The focus groups were semi-structured with a few guiding questions about participants' health concerns and health insurance presented by the principal investigator. Researchers provided participants advance copies of the questions, and prefaced the sessions with statements indicating that participants did not have to respond to a particular question if they were uncomfortable doing so, and that all information shared in the focus groups remained in the room (i.e., all members needed to respect other members' privacy). Specifically, we asked each group:

1) What do (did) you like about your high risk pool insurance plan? What, if anything, has been problematic?

2) Have high premiums or deductibles ever prevented you from getting health care you need? 
a. If so, what kind of care has been difficult to afford?

b. If you have hesitated to seek care, has it affected your health?

For focus group sessions with individuals receiving intervention, that is, DMIE benefits, we also asked:

3) Has your DMIE coverage changed your ability to get the health care you need? If so, how?

\section{Qualitative Analysis}

The sessions were recorded and transcribed with Express Scribe, a software application that allows the replay of digitally recorded sound data on the computer. ${ }^{29}$ A single researcher, who was trained in qualitative methods and not in attendance at the focus group sessions, separated the transcripts into intervention and control groups and analyzed each group using pile

sorting and theme identification techniques. ${ }^{30}$ On initial review, she highlighted all information that appeared to be relevant and developed preliminary themes and topics. She reviewed the transcripts again, pile sorted the information based on previously identified topics, and reviewed the sorted information to confirm themes. She then compared themes between intervention and control group members. The two researchers who conducted the focus groups reviewed and concurred with the themes. The three most salient of these themes, presented here, were similar between groups, with differences expressed only in terms of how early experiences with the DMIE helped eliminate or reduce the problems intervention group participants had previously encountered. 


\section{RESULTS}

\section{Participant Demographics}

Fifty-two percent of the focus group participants were female, which slightly overrepresents women compared to all DMIE study participants (50\% female). Focus group participants' ages were representative of the entire DMIE study sample with ages ranging from 29 to 62 years and an average age of 52 (Table 1). These individuals reported a variety of chronic and potentially disabling health conditions including: heart disease; current and past cancers; transient ischemic attacks and strokes; mental illnesses such as anxiety, depression, bipolar disorder, and posttraumatic stress disorder; asthma; arthritis; diabetes; epilepsy; hypertension; spinal injuries or disease; multiple sclerosis; chronic obstructive pulmonary disease; hepatitis C; sleep apnea; and systemic lupus. Their conditions are similar to those reported by all DMIE enrollees.

Focus group participants were well educated and middle class; 93\% had completed at least some college and the group had a mean annual personal income of about $\$ 47,000$ and household income of $\$ 67,000$ (Table 1). Nevertheless, some $27 \%$ reported having medical debt despite coverage through the high risk pool, prior to DMIE enrollment. Most of the study participants (65\% of focus group members and $70 \%$ of the entire DMIE sample) were selfemployed and therefore could not access employer-based group health insurance coverage. ${ }^{12}$ Almost half were not married and therefore were not able to assess coverage through a spouse's insurance plan.

\section{Focus Group Themes}

Focus group participants from both the intervention and control groups raised similar concerns about the cost of health care and the inadequacy of high risk pool coverage to meet 
their needs. These cost concerns were often the single strongest determinant of participant's health care behaviors and decision-making. Moreover, the focus groups' discussions and comments elucidate these themes, which were also evident from a survey of the entire DMIE sample. $^{12}$

Theme 1: High premiums and deductibles limit ability to afford basic health services and lead to a large amount of unmet medical need. In the high risk pool, plans with lower deductibles charge substantially higher premiums; so many participants indicated that they chose high deductible plans in order to obtain affordable premiums. As one female participant working as a human resources manager explained: "I chose the high deductible to make it an affordable premium for me. I also decided that should anything happen, like a car accident that might incapacitate me, that we would sell the house." The majority of participants in the DMIE study were enrolled in plans with a $\$ 2,500$ or higher deductible; $31 \%$ of focus group participants had a $\$ 7,500$ deductible (Table 2). Overall, their monthly average premiums were $\$ 448 .{ }^{12}$ Having a high deductible means that these individuals must pay for all of their health care costs out of pocket until the deductible is met. As a result, many focus group participants reported that they often chose not to access services when needed.

\section{Table 2}

Kansas High Risk Pool Plan Deductibles, Premium, and Enrollment Distributions

\begin{tabular}{lcccc}
\hline Plan name & $\begin{array}{c}\text { Annual } \\
\text { deductible }\end{array}$ & $\begin{array}{c}\text { Monthly } \\
\text { premium* }\end{array}$ & $\begin{array}{c}\text { DMIE enrollment } \\
\text { distribution } \\
(n=414) \dagger\end{array}$ & $\begin{array}{c}\text { Focus group enrollment } \\
\text { distribution } \\
(n=42)\end{array}$ \\
\hline Plan A & $\$ 500$ & $\$ 878$ & $4 \%$ & -- \\
Plan B & $\$ 1,000$ & $\$ 592$ & $19 \%$ & $21 \%$ \\
Plan C & $\$ 1,500$ & $\$ 681$ & $20 \%$ & $19 \%$ \\
Plan D & $\$ 2,500$ & $\$ 623$ & $10 \%$ & $7 \%$ \\
Plan E & $\$ 5,000$ & $\$ 339$ & $28 \%$ & $21 \%$ \\
Plan F & $\$ 7,500$ & $\$ 264$ & $21 \%$ & $31 \%$ \\
\hline
\end{tabular}

* Monthly premium during calendar year 2007 for enrollees in the age group 50-59 years.

$\dagger$ Unknown plan enrollments, $n=2$. 
Focus group participants reported delaying or forgoing all types of needed medical care, including diagnostic, preventive, or treatment services due to the out-of-pocket costs. Because they could not afford to seek care, many never met their deductible. An analysis of health insurance claims made one year prior to the study confirmed that $27 \%$ of all DMIE participants, not just those in the focus groups, who had received medical services were not reimbursed for services because they did not meet their deductible. Focus group participants reported a variety of coping strategies. Primary among these strategies was an attempt to "save up" needed services until the combined cost of treatments was enough to meet deductibles. In the words of a 61 year old, male business manager,

If I'm not going to hit \$5,000 [his deductible], I'm not getting it done. If this is a year for a shoulder surgery, okay then I'm going to get the hernia fixed, I'm going to get the glasses. You know you do that. I had a stomach wall hernia that I had to wait for three years until I had a shoulder surgery and I got the hernia fixed December 1 and the shoulder surgery December 23.

The second most frequently discussed strategies were to forgo care entirely or wait until a condition became life threatening. In association with the former, some participants reported they were unable to complete treatments because a change in the calendar year reset their deductibles. As a 56 year old, male small business owner explained, "Cardiac rehab...I went through that program...I was in the program for several weeks until the magical 2007 rolled around and my deductible just started all over again, so I opted out."

Participants often reported that their failure to seek care and forced delays in treatment resulted in exacerbated conditions and unmet medical need. Intervention group participants, who were better able to have their needs met by the DMIE program, went into more depth about 
experiences with delays and discussed their subsequent relief at receiving treatment. A 60 year old, male small business owner with diabetes and chronic kidney problems said, ...Since getting accepted into this [study], I've seen a kidney specialist and a brand new urologist and I'm having an in-depth renal scan done tomorrow. One of the big things that was so terrific for me to get in this study is that I've got this rather long nasty stent in me that doctors say you should have removed and changed about every six to eight months, and the one I have in me right now I've had for two and a half years.

\section{Theme 2: Individual prescription costs are high and medications are difficult to afford,} which leads to poor medication compliance. The costs of prescription drugs in the Kansas high risk pool coverage apply to an individual's deductible, so he or she must pay the full cost of medications out of pocket until the deductible is met. After the deductible is met, prescriptions are covered at $50 \%$. Focus group participants reported that prescription costs are prohibitive and they have devised a variety of ways to reduce them. Some reported cost saving methods were those encouraged by medical professionals, such as requesting generics, free samples, or purchasing double dose pills to cut in half. Given the nature of the conditions experienced by DMIE participants, however, generic medications are either unavailable (e.g., insulin) or often are not included in the $\$ 4$ formularies at discount pharmacies.

Some additional strategies devised by the focus group members were non-detrimental, such as using Veteran's Administration (VA) benefits, while others were not so benign. Some participants refused prescriptions, delayed filling them, reduced dosages below prescribed levels, skipped doses entirely, or finished prescriptions that were no longer prescribed because they had already paid for them. As a 62 year old, self employed male engineering consultant reported, 
...it is just that I've found that you can take one less or two less pills a day a week and the pharmacist says it doesn't make any difference. I take insulin and I cut my insulin in half...

Failure to take medications as prescribed was rationalized by focus group members as acceptable. Participants assumed, for example, that because complete compliance was impossible, medications were designed so that skipping a few doses would not be harmful. "I'll bet that that isn't such a big deal because compliance, absolute perfect compliance, in taking meds is really hard to maintain," a 60 year old, self-employed woman explained. Some participants saw the situation as a measure of individual responsibility. 'It's not like you're really taking risks; you're taking responsibility for your own medical care. I assume a lot of people are doing that," a 50 year old, male self-employed insurance broker said.

While intervention and control group members reported many of the same coping strategies before the study, intervention participants did not report such rationalizations after early-stage experiences with DMIE benefits. Instead, they talked about their relief that they could now afford their prescriptions. A 45 year old, female financial planner discussed her medication use before DMIE, ...count the pills and know how many you have, to spread them out between doctor's visits because you can't pay for the prescription. Because I was paying the high premium, I didn't have enough left to pay for the prescription and then I would just count them and spread them out... 
Her behavior changed after enrollment in DMIE,

...now that I've gotten the lower premiums and can afford the medication, I take the pills every day exactly like they're written on the prescription bottle, and check my sugar three times a day like I'm supposed to... because even the little bottle of strips cost $\$ 85$ a box.

Theme 3: Delay or forfeit strategies used for treatment (medical care and prescriptions) increase stress and diminish health and quality of life. Not being able to afford medical care caused participants a great deal of stress both in terms of not having care as well as depleting savings needed for other necessitates. Participants explained that making health decisions based on cost was demoralizing. A 54 year old, female retail consultant who had abnormal mammograms reported,

I know that I worry about it and that's worse. You know you're going, 'okay is this other pain something that I should have gotten tested and then the tests would have shown a residue or something'...I couldn't afford this so don't even worry about it. Don't think about it, but you know you worry.

A 56 year old, male sales manager expressed similar thoughts,

If somebody says you ought to do this [medical test] and all of a sudden you're saying I don't think I can do it because I can't afford it... and then you go home at night and you say, well—did I really do the right thing? I mean, that eats on people.

For some participants, medical need priorities were based primarily on cost, and their inability to afford care was overwhelming. "I've done all the standard doctor things and I'm kind of afraid to-I know there's some other problems — and I'm kind of afraid to start spending my money just hit and miss," said a 56 year old, male retail shop owner. For others, priorities were based on a combination of cost and non-medical assumptions about the human body. Some 
people seemed to see their bodies as machines and did not realize that failure to take care of one problem might affect other body systems. ${ }^{46}$ This mindset was most evident in intervention group members who, after they were able to seek care, found out about the overall effect of their delays. A 40 year old, male shop assistant explained,

I did not control the sleep apnea because of the price of the machine... I stayed away from my doctors for awhile until I had paid them because I did not want to go back in with a huge bill and ask them to do more work on me. So now I'm here and I find out that probably I did the wrong thing... The decisions I made to save money with the constraints of the insurance money were all the wrong ones. I was target-fixated. I was fixated totally on the heart, and the sleep apnea didn't seem that troublesome. So what if I was a little bit tired? I was used to working on the night shift and doing double shifts and working lots of overtime, so I was used to being tired.

Participants reported feeling disheartened and discouraged by their situations. In the intervention group, continuous uncertainty about getting appropriate care prior to DMIE benefits was described as "having a cloud over your head." From the control group, another participant said, “I mean, I'm a pretty upbeat person. I'm not a negative person, but I don't know what to do; I don't know where to turn; I don't know who to talk to." Participants' discussion of their involvement in the intervention group elucidated their reported previous feelings about being unable to afford health care. One participant said it was "like I hit the lottery." Other people reported that they believed the reduction in cost-related stress would help them improve their future health. A 40 year old, female, self employed software engineer explained, Being in this program has helped take the stress off the struggles. I mean, I don't have to worry about how I'm going to pay my medical bills while I'm on the program, and I take 
that energy and I channel it back into my work, you know, trying to build a life for myself and money for myself so when it's over I can help myself.

\section{CONCLUSION}

Other research has shown that consumers in both the group and private insurance markets appeared averse to deductibles more than $\$ 1,000$; only $8 \%$ of those with group insurance and $34 \%$ of those with private insurance had such a deductible. ${ }^{32,33}$ As discussed earlier, multiple studies indicate increased cost sharing results in decreased utilization of services and poor medication compliance. Our focus group findings illustrate ways that some people rationalize their behaviors when they forgo needed services due to an inability to pay for them.

Research on group health plans suggests that, given a choice, people would prefer to pay more for less restricted coverage. ${ }^{22}$ Focus group participant comments indicated that their selection of plans with a high deductible was based almost entirely on how much they could afford to pay for a monthly premium and still meet other basic needs. They simply could not afford comprehensive coverage through the risk pool. In many of these cases, people with high deductibles also had a limited ability to pay out of pocket for care. This finding corresponds to those of previous research focused on cost sharing that found that an increased patient cost reduced care for minor and major symptoms among the chronically ill. ${ }^{28}$ Some policy makers suggest high deductibles and other forms of increased cost-sharing for health expense reduction cause patients with these deductibles to make more cost-conscious care decisions. ${ }^{34}$ Findings here suggest high deductibles do not encourage better choices that reduce cost but impede patient access to needed services, which results in greater expense when such delays are detrimental to health and mental well-being. The potential for negative outcomes may be especially large 
among this population experiencing a range of potentially disabling mental and physical health conditions.

As was suggested by earlier studies of medication compliance in association with prescription cost, inability to afford prescriptions leads to poor compliance in the uninsured or underinsured, elderly, and chronically ill, often with the result of poor health outcomes. ${ }^{19,35-38}$ Multiple sources also indicate that provision of medications at or for reduced cost not only increases compliance and thus improves health, but, because medications are often less expensive than non-compliance related complications, decreases costs of care. ${ }^{36,38}$ Studies that consider cost and compliance often use survey or medical records data, and little research addresses individuals' thoughts associated with cost-related non-compliance. Our study suggests participants understand maintaining compliance is ideal; thus, they actively rationalize their inability to obtain medication in a way that alleviates stress associated with falling short of the proper health care. Once provided medication at an affordable price-intervention group members pay a \$3 co-pay per prescription - participants were excited about their ability to maintain compliance. Indeed, the two services most utilized by intervention group members after eliminating their deductibles were pharmaceuticals and diagnostic procedures, indicating a recognition that these fundamental needs should be met when financially possible.

Just as the RAND health insurance experiment found that consumers faced with higher cost sharing reduced utilization of health services across the board, we also found that high costs were associated with self reported reductions in services. ${ }^{9}$ Our research differs because it shows how people rationalize what they realize are probably bad decisions. They know their behaviors jeopardize their health and yet they feel powerless to change them. Our focus group participants 
articulate how the stress that is associated with difficult care decisions demoralizes and overwhelms people.

\section{Study Limitations}

Although this study is limited to a single state, studies based on small, geographically limited samples can be helpful for highlighting the need for more work in understanding broader needs. ${ }^{39}$ Our findings are limited by the DMIE participation criteria (i.e., age, employment, and potentially disabling condition thresholds), but are representative of at least a subset of risk pool participants. Finally, focus group participation was limited to volunteers from DMIE who were able to attend scheduled sessions. Focus group data is suggestive, but exploratory. Cautions against generalizing these data to all high risk pool members or the general population are, therefore, warranted.

\section{SO WHAT?}

Despite the fact that focus group members were well-educated and middle-class individuals, the evidence suggests that their medical behaviors and decisions were not based on sound medical judgment but on inability to afford services. Such behaviors as "saving up" needed services to meet a deductible and skipping or inappropriately using prescription medications were commonly reported — as were increased levels of stress and anxiety due to concerns about unmet health care needs. Many people reported adverse outcomes due to delayed care. When relieved of a deductible obligation, participants cited increased use of such appropriate medical care as diagnostic testing and prescription medications. High deductible plans or plans with greater cost-sharing may be especially problematic for a high-risk population that experiences a variety of potentially disabling mental and physical health conditions. 


\section{REFERENCES}

1. Pollitz K, Bangit E. Federal Aid to State High-Risk Pools: Promoting Health Insurance

Coverage or Providing Fiscal Relief? The Commonwealth Fund, Issue Brief 875. 2005.

Available at: www.cmwf.org. Accessed March 12, 2008.

2. Kaiser Family Foundation, The. State High Risk Pool Costs 2006: State Health Facts.

Available at http://www.statehealthfacts.org. Accessed March 12, 2008.

3. Chernew ME, Gibson TB, Yu-Isenberg K, Sokol MC, Rosen AB, Fendrick AM. Effects of increased patient cost sharing on socioeconomic disparities in health care. J Gen Intern Med. 2008. $23 ; 1131-1136$.

4. Gibson TB, McLaughlin CG, Smith DG. A copayment increase for prescription drugs: The long-term and short-term effects on use and expenditures. Inquiry. 2005;42:293-310.

5. Gibson TB, Ozminkowski RJ, Goetzel RZ. The effects of prescription drug cost sharing: A review of the evidence. American Journal of Managed Care. 2005;11:730-740.

6. Goldman DP, Joyce GF, Escarce JJ, Pace JE, Soloman MD, Laouri M. Pharmacy benefits and the use of drugs by the chronically ill. JAMA. 2004;291:2344-2350.

7. Huskamp HP, Deverka PA, Epstein AM, Epstein RS, McGuigan KS, Frank RG. The effect of incentive-based formularies on prescription-drug utilization and spending. $N$ Engl J Med. 2003;349:2224-2232.

8. Landsman PB, Yu W, Liu X, Teutsch SM, Berger ML. Impact of 3-tier pharmacy benefit design and increased consumer cost-sharing on drug utilization. The American Journal of Managed Care. 2005;11:621-628. 
9. Siu AL, Sonnenberg FA, Manning WG, Goldberg GA, Bloomfield ES, Newhouse JP, et al., Inappropriate use of hospitals in a randomized trial of health insurance plans. $N$ Engl J Med. $1986 ; 315: 1259-1266$.

10. Tamblyn R, Laprise R, Hanley JA, et al. Adverse events associated with prescription drug cost-sharing among poor and elderly persons. JAMA. 2001;285:421-429.

11. Trivedi AN, Rakowski W, Ayanian JZ. Effect of cost-sharing on screening mammography in Medicare health plans. N Engl J Med. 2008;358:375-383.

12. Hall JP, Moore JM. Does high risk pool coverage meet the needs of a population at risk for disability? Inquiry. In press.

13. Kansas Health Policy Authority. Demonstration to Maintain Independence and Employment. U.S. Department of Health \& Human Services, Centers for Medicare \& Medicaid Services Grant \#11-P-92389/07-01.

14. Hall JP, Moore JM. Historical Disability Outcomes of Enrollees in the Kansas High-Risk Pool: A White Paper Presented to CMS by the Kansas DMIE Project. January 2006. Available at http://das.kucrl.org/dmie.shtml. Accessed October 4, 2007.

15. Sheffet AM, Ridlen S, Louria DB. Baseline behavioral assessment for the New Jersey Health Wellness Promotion Act. Am J Health Promot. 2006;20:401-410.

16. Chernew, M. Cost sharing in health care markets. Testimony before the Subcommittee on Health of the House Committee on Ways and Means. May 14, 2008.

17. Goldman DP, Joyce GF, Zheng Y. Prescription drug cost sharing: Associations with medical utilization and spending and health. JAMA. 2007;298:61-69.

18. Hsu J, Price M, Huang J et al. Unintended consequences of caps on Medicare drug benefits. N Engl J Med. 2008;354:2349-2359. 
19. Chernew ME, Shah MR, Wegh A, et al. Impact of decreasing copayments on medication adherence within a disease management environment. Health Aff. 2008:27;103-112.

20. Pollitz K, Sorian R, Thomas K. How accessible is individual health insurance for consumers in less-than-perfect health? The Kaiser Family Foundation, Publication \#3133. 2001.

21. National Association of State Comprehensive Health Insurance Plans (NASCHIP). Comprehensive health insurance for high-risk individuals-A state-by-state analysis, Twentieth edition. Burnsville, MN: NASCHIP; 2006.

22. Kaiser Family Foundation, The. 2003 Health Insurance Survey. 2004. Available at http://www.kff.org/kaiserpolls/pomr110104pkg.cfm. Accessed October 6, 2008.

23. U.S. Department of Health and Human Services, Centers for Medicare and Medicaid Services (CMS). HHS award grants to twenty-two states to offset costs of insurance for residents too sick for conventional coverage. Washington, DC: U.S. Department of Health and Human Services; October 2005. Available at http://www.hhs.gov/news/press/2005pres/20051005a.html. Accessed on October 9, 2008.

24. Chollet, D. Expanding individual health insurance coverage: Are high-risk pools the answer? Health Aff Web Exclusive. February 23, 2003 10.1377/hlthaff.w2.349.

25. Ladenheim K. High-risk insurance pools: Safety net or tightrope? National Conference of State Legislatures Legisbrief. April/May 2004: 12; 1-2.

26. Owen, M. State high-risk pools: A weighty health care burden. Risk \& Insurance. 2004:1-2.

27. Kaiser Commission on Medicaid and the Uninsured (Kaiser). Fact sheet (\#4060)

Underinsured in America: Is health coverage adequate? 2002. Available at http://www.kff.org/uninsured/4060-index.cfm. Accessed October 4, 2007. 
28. Wong, M., R. Andersen, C. Sherbourne, R. Hays, and M. Shapiro. Effects of cost sharing on care seeking and health status: Results from the medical outcomes study. Am J Public Health. 2001: 91; 1889-94.

29. NCH Software. Express Scribe Transcription Playback Software: Digital Transcription Audio Player Software. Canberra, Australia: NCH Software Pty Ltd; 2007.

30. Bernard R. Research Methods in Anthropology: Qualitative and Quantitative Approaches. Lanham, MD: Altamira; 2006.

31. Martin E. The end of the body? American Ethnologist 1990; 19:121 - 140.

32. Kaiser Family Foundation, The. Employer Health Benefits: 2004 Annual Survey. Available at http://www.kff.org /insurance/7148/upload/Employer-Health-Benefit-Survey-2004Chartpack.pdf. Accessed March 12, 2008.

33. Turnbull N, Kane N. Insuring the Healthy or Insuring the Sick? The Dilemma of Regulating the Individual Health Insurance Market Findings from a Study of Seven States. The Commonwealth Fund, Publication 771 Available at: http://www.commonwealthfund.org/usr_doc/771_Turnbull_insuring_healthy_or_sick_findings.p df?section=4039. Accessed March 12, 2008.

34 Davis K, Doty M, Ho A. How High is Too High? Implications of High-Deductible Health Plans. The Commonwealth Fund, Publication 816. 2005. Available at: http://www. commenwealthfund.org/publications/publications_show.htm?doc_idz274007 Accessed March $12,2008$.

35. Luthy K, Peterson NE, Wilkinson J. Cost-efficient treatment for uninsured or underinsured patients with hypertension, depression, diabetes mellitus, insomnia, and gastroesophageal reflux. American Academy of Nurse Practitioners. 2008;20:136-143. 
36. Rosen A, Hamel MB, Weinstein M, Cutler D, Fendrick AM, Vijan, S. Cost-effectiveness of full Medicare coverage of angiotensin-converting enzyme inhibitors for beneficiaries with diabetes. Ann Intern Med. 2005;143:89-99.

37. Piette J, Heisler M, Wagner T. Cost-related medication under use: Do patients with chronic illnesses tell their doctors? Arch Intern Med. 2004;164:1749-1755.

38. Choudhry N, Avorn J, Antman E, Schneeweiss S, Shrank W. Should patients receive secondary prevention medications for free after a myocardial infarction: An economic analysis. Health Aff. 2007;26:186-194.

39. Long S, King J, Coughlin T. The implications of unmet need for future health care use: Findings for a sample of disabled Medicaid beneficiaries in New York. Inquiry. 2006;42:413420. 